\title{
Instituições e poder: racionalidade macropolítica e genealogia
}

\author{
Lilia Ferreira Lobo \\ Universidade Federal Fluminense
}

\begin{abstract}
Resumo
Partindo da crítica de Guilhon de Albuquerque, em seu livro Instituições e Poder, a Irving Goffman, em Manicômios, Prisões e Conventos, sobre as instituições totalitárias, este trabalho pretende: (1) questionar os pressupostos teóricos e os esquemas de análise de Guilhon de Albuquerque para a concepção de instituição e de instituição totalitária a partir de uma racionalidade macropolítica; e (2) contrapor a esta perspectiva uma outra ordem de pensar as instituições, um pensar genealógico que privilegia, dentre outros pontos, as produções (no lugar das representações); os processos de constituição (no lugar das formas constituídas); as irrupções (no lugar das interrupções); as positividades (no lugar das interdições e das faltas).
\end{abstract}

Palavras-chave: instituição; poder; genealogia

\begin{abstract}
Institutions and power: macropolitical rationale and genealogy. Based upon the criticism presented by Guilhon de Albuquerque in his book Instituições e Poder to Irving Goffmann's Asylums - Essays on the social patients and other inmates regarding totalitarian institutions, this work intends: (1) to question Guilhon de Albuquerque's theoretical premises and analysis schemes for the conception of institution and totalitarian institution based on macro political rationale; and (2) to contrast this perspective against a different thinking process on the institutions, a genealogical thinking which privileges, among other aspects: the productions (instead of the representations); the constitution process (instead of constituted forms); the irruption (instead of the interruption); and the positivity (instead of the interdiction and need).
\end{abstract}

Keywords: institution; power; genealogy

$\mathrm{A}$ intenção inicial deste trabalho foi a de analisar o livro Manicômios, Prisões e Conventos de Irving Goffman (1974), para cuja tarefa me foi sugerida como pista o livro de J. A. Guilhon de Albuquerque, Instituição e Poder (1980), já que este último servia ao meu propósito. No decorrer da leitura dos dois livros gradativamente minha atenção foi desviada para o segundo, pelas questões que coloca a respeito dos problemas teóricos e metodológicos do objeto do conhecimento que o autor pretende resolver, como ele próprio anuncia na introdução do seu livro, em especial, as questões da análise concreta das instituições totais (ou totalitárias) ${ }^{1}$, objeto do citado livro de Irving Goffman.

Não só por isso. E as razões desse interesse são de duas ordens:

É que Guilhon de Albuquerque (G. A. $)^{2}$, ao tornar explícitos seus pressupostos de pensamento (o que, de resto, não aparecem no livro de Goffman), apresenta os critérios de racionalidade de uma perspectiva que entendo ser macropolítica das instituições. Talvez aí esteja o mérito maior do seu trabalho: ao desnudar as regras com as quais trabalha, acaba por instigar o leitor a analisar sua análise, a avaliar sua utilidade prática, segundo estas mesmas regras.
A segunda ordem de interesse, a que me importa mais diretamente, é a possibilidade que o livro de G. A. abre para o confronto com outra ordem de pensar, que se pretende também um rigor, um outro rigor, não propriamente para a resolução dos problemas teóricos e metodológicos e a "demonstração de sua utilidade prática nas análises concretas" (Albuquerque, 1980, p. V), objetivo de Instituição e Poder, mas um dispositivo de pensar que pode produzir outros problemas através do que se pode chamar de pressupostos micropolíticos ou genealógicos de análise.

Sem ter qualquer pretensão de esgotar as questões colocadas em cada uma dessas perspectivas, a divisão deste trabalho segue as duas ordens de interesse que o livro de G. A. me suscitou. Trata-se, portanto, em uma primeira aproximação, de um levantamento de alguns pontos para reflexão e que talvez mereçam aprofundamento posterior.

\section{Alguns pontos para análise "de dentro" de uma racionalidade macropolítica das instituições}

Como se constitui uma análise teórica? Quando se pode dizer que uma análise está bem constituída? Quaisquer que sejam as respostas formuladas a estas questões, elas terão 
necessariamente em seu bojo concepções diferentes sobre a natureza do conhecimento - natureza esta historicamente mutante, atravessada por forças históricas bem diferentes:

Da suposição de que há uma verdade invariante mais ou menos evidente nas coisas e que se pode simplesmente constatar ou trabalhosamente desvelar, à busca de um absoluto oculto a conhecer, de tal forma distante que não se teria qualquer garantia de se estar cada vez mais próximo dele;

De uma desconfiança no uso das palavras e sua maior ou menor capacidade de dizer algo verdadeiro sobre as coisas, ao reconhecimento de que elas nomeiam imagens desde já submetidas às perspectivas de quem olha e que, ainda assim e por isso mesmo, seria necessário estabelecer regras de correspondência e de adequação das representações para não se cair no puro ceticismo;

De uma concepção de que o conhecimento como apreensão da realidade supõe uma harmonia com esta, à sua caracterização como processo de desmontagem, como fazem os práticos com os seus objetos de trabalho, não só para ver como funcionam por dentro a fim de remontá-lo, mas para produzir novos objetos - “... sempre existe transformação, produção de um novo objeto, doravante dominado, tanto na ordem das coisas como na ordem do pensamento" (Albuquerque, 1980, p. 2).

Como Guilhon de Albuquerque (1980) explicita desde o prefácio que partirá desta última concepção ${ }^{3}$, ou seja, do conhecimento como processo de produção, irá discutir na primeira parte do livro os procedimentos e esquemas de análise (montagem e desmontagem) chamando de início a atenção para a premissa segundo a qual "é preciso que os princípios de análise sejam os princípios do modo de produção do objeto produzido/dominado" (p. 2). Será, portanto, desta perspectiva que, ao mesmo tempo em que tenderá a reinterpretar o estudo de Goffman sobre as instituições totais, procurará testar na análise concreta a validade do esquema que propõe.

Partirei, então, de três pontos selecionados na leitura de seu livro em que se assenta, a meu ver, o que se pode chamar de racionalidade macropolítica das instituições.

\subsection{Sobre a tripartição da análise e a distinção entre plano de análise e plano de racionalidade}

Para o autor, "a questão de saber quantos e quais elementos constitutivos em que se pode - ou deve - analisar uma realidade social é um problema teórico da mais estreita relevância em termos de investigação" (p. 3), o que significa proceder como a química: ao fracionar um objeto em partes constitutivas é preciso levar em conta que "qualquer resultado da análise depende dos procedimentos analíticos" (p. 3), ou seja, depende de como se opera a análise. Trata-se, portanto, de um deslocamento da questão epistemológica da essência do conhecimento para o de sua produção, realizado por Althusser. Será também da perspectiva de Althusser que o autor irá propor seu esquema de análise, através do qual irá, por sua vez, formular uma crítica a Althusser sobre certas dificuldades teóricas, principalmente no que tange ao papel da ideologia (Althusser, 1985) enquanto reprodução da força de trabalho e da escola como um dos aparelhos ideológicos de Estado.
Assim, coloca a questão da tripartição da análise no plano central das discussões, nos seguintes termos: (a) a questão da produção de conhecimentos; (b) a relação entre as instâncias na estrutura social e (c) a articulação entre estas duas questões na resolução do problema da natureza e do funcionamento das instituições (p. 3).

A solução de conjunto para o problema das relações entre o ideológico, o econômico e o político, proposto por Althusser, merece do autor algumas críticas:

Sobre o papel da ideologia como reprodução da força de trabalho, no caso a escola contribuindo para a sua qualificação: que faz a ideologia? Reproduz a força de trabalho e o lugar do trabalhador - lugar que ocupa nas relações de produção, daquele que não é proprietário dos meios de produção e, portanto, vende o único bem que lhe pertence: a força de trabalho. Para o autor, a ideologia não reproduz a força de trabalho, ela tem um efeito de reconhecimento, ela reproduz uma imagem que o trabalhador faz de si próprio e do seu lugar. Não reproduz tampouco uma ordem social, apenas o reconhecimento desta.

A crítica do papel da ideologia em Althusser revela a preocupação extrema de G. A. em distinguir entre o que chama de plano de realidade e plano de análise, em não confundir o pensamento com o real. "As instituições concretas não são nem aparelhos, nem práticas, muito menos possuem um lugar designado numa instância. Não mais do que indivíduos, não constituem suporte de coisa alguma, são apenas referentes da análise" (p. 9). E mais adiante indaga:

O que é uma instituição concreta? É um conjunto discreto de coisas (entre as quais indivíduos) que nada distingue (na sua própria essência, assim como na sua natureza de conjunto) de outras coisas. Chamar esse conjunto de "instituição" é uma operação de duplo alcance (uma operação, portanto, um trabalho): nomeando-o constituímo-lo enquanto conjunto. Tanto é verdade que posso considerar os prédios como parte do conjunto -nomeado- instituição e posso não fazê-lo segundo o conjunto que defino ao nomeá-la. (p. 9, grifo do autor)

A totalidade concreta "instituição já é, portanto, fruto de um trabalho de abstração (ou, se se prefere, fruto de um trabalho de produção de um objeto de pensamento). Mas a constituição de uma totalidade concreta é muito pouco para um trabalho teórico" (p. 21), segundo determinantes da própria teoria. Isto significa que, se se quiser fugir de uma terminologia essencialista, será necessário entender que uma proposição do tipo a escola é um sistema de reprodução da ideologia dominante refere-se à totalidade empírica escola (não mais a este ou aquele estabelecimento), totalidade esta cuja pertinência interpretativa se à sua análise em termos de aparelho ideológico de Estado - "uma entidade teórica designa sempre uma propriedade que, se é observável, pode ser interpretada em termos de propriedades empíricas de uma totalidade, jamais em termos de totalidades enquanto tais" (p. 16). O engano de nomeá-las, multiplicando suas propriedades exaustivamente, levaria no máximo à elaboração de um extenso catálogo de nomes, uma confusão entre o plano da teoria e o plano da realidade, jamais à produção de conheci- 
mento. "Por onde surge a categoria da totalidade, desaparece o rigor científico" (p. 26).

Melhor que a crítica (a meu, ver injusta) do autor à maneira como a análise institucional opera este tipo de confusão ${ }^{4}$ (que discutirei mais adiante), temos o exemplo do estudo de Goffman. Embora não chegue àquele extremo tão simplista, Goffman (1974) tenta extrair um perfil geral da lista de estabelecimentos que chama de instituições totais, descrevendo atributos nem sempre comuns a todas elas:

o que distingue as instituições totais é o fato de cada uma delas apresentar em grau intenso muitos itens dessa família de atributos ${ }^{5}$. Ao falar de características comuns usarei a frase de forma limitada, mas que me parece logicamente defensável. Ao mesmo tempo, isso permite usar o método de tipos ideais, através do estabelecimento de certos aspectos comuns, com a esperança de posteriormente esclarecer diferenças significativas. (p. 13)

Afirma, mais adiante (p. 108), que sua pretensão é fazer uma definição denotativa das instituições totais, ou seja, indicar (denotar) características gerais e chega a descrevê-las tão minuciosamente que deixam de ser gerais (talvez seja por isso que seu livro se torne tão interessante...). Mas, ao restringir-se ao interior desses estabelecimentos, descontextualizando-os do meio em que se inserem, dos efeitos que provocam e dos serviços que prestam à sociedade mais ampla, promove uma espécie de coisificação que Guilhon de Albuquerque denuncia como um certo tipo apriorístico de instituição em si, um dado da realidade, "as totalidades enquanto tais" - um exemplo de confusão entre plano da teoria e plano da realidade.

O que G. A. chama de instituições totalitárias refere-se ao caráter político, tomado como repressivo, predominante nestas instituições. Utiliza a terminologia de Althusser que identifica o repressivo ao político (assim como a função de soberania, numa visão centralizada e centralizadora de poder). Contudo, para o autor, instituição totalitária não é sinônimo de aparelho repressivo, uma vez que este pode ser encontrado em outras formas sociais. Ao introduzir a categoria dos aparelhos na análise das instituições totalitárias, G. A. procura afastar as dificuldades da conceituação destas por Goffman que, por oscilar entre dois modos de institucionalização diferentes $^{6}$, fracassa na proposta de conceitualização ideal-típica. Por isso, G. A. pretende esclarecer critérios precisos para caracterizar o que é ou quando se pode chamar uma instituição de totalitária: o critério da existência de dois tipos empíricos de formas sociais (com dominante e com dominância de um dos aparelhos) (Albuquerque, 1980, p. 104) e o critério de extraterritorialidade do aparelho econômico (p. 26 e seguintes). Mais adiante voltarei a esta questão.

Neste ponto, vou me limitar a algumas considerações sobre seus pressupostos a respeito da separação e os modos de articulação entre o ideológico e o repressivo:

Não é somente em G. A. que os termos ideologia e repressão são confusos. Mesmo este autor, tão obcecado pela ordem e pela precisão, não consegue fugir à ambigüidade e principalmente às antinomias que estes dois termos sugerem.
E isto porque a análise marxista de onde extrai, mesmo criticando, seus principais pressupostos (Althusser), fica no meio do caminho no que se refere ao conhecimento como processo de produção - mantém a verdade como fim (finalidade trans-histórica e transcendental a atingir no bojo das teorias, com suas regras paradigmas e métodos) e não como meio (estratégia histórica de produção de verdades). Assim é que mantém, em conseqüência, duas antinomias: as separações entre ideologia e ciência (o subjetivo e o intersubjetivo, respectivamente) e entre corpo e alma (o comportamento e as representações). Na primeira, a ideologia é apresentada ora como um imaginário subjetivo que perturba e obscurece o saber científico, ora como um imaginário de classe que reproduz o reconhecimento da ordem social vigente - em ambos os casos uma falsa consciência. Um efeito de ocultamento. A ciência, como tal, teria de se livrar dos efeitos ideológicos (subjetivos) para produzir uma verdadeira teoria, dentro dos cânones de intersubjetividade de verdade e falsidade que validam os métodos e a estrutura formal das teorias. $\mathrm{Na}$ segunda antinomia, o que aparece é a separação do corpo, com a materialidade concreta de seus comportamentos sobre os quais incide a repressão (e seus efeitos de interdição e de dominação) e a alma, o subjetivo ao nível das imagens representações $^{7}$, das atitudes, e sobre o qual incidem a inculcação e a persuasão, tomadas aqui como ideológicas.

Para não ficar apenas no meio do caminho e tomar para sempre as verdades como meio, como produções estratégicas, abandonando de vez qualquer fundo trans-histórico remoto ou de um lugar ainda que vazio de sujeito de conhecimento (e de objeto a conhecer), é preciso apelar para Foucault, que nos mostra em seus estudos genealógicos:

- como os agenciamentos de certas práticas (dispositivos) produzem objetivações no mundo (os objetos e as formas dos saberes, objetivações estas que não são nem mais nem menos verdadeiras), sendo o próprio sujeito uma objetivação da história;

- como os agenciamentos de certas práticas que são sempre práticas de corpos (e não são nem ideológicas, nem repressivas) são políticas, (as relações de poder) produzem efeitos de sujeito (uma alma, uma psiquê), historicamente datados.

Sobre a questão da extraterritorialidade do aparelho econômico, G. A. inicia por descrever as formações medievais, como unidades sociais soberanas (como esferas separadas e autônomas da ordem social medieval) que, além de terem uma administração formal (estrutura burocrática com aparelhos repressivos especializados), eram ao mesmo tempo unidades econômicas e de vida social. Isto quer dizer que não possuíam um aparelho econômico específico, o que somente passou a existir a partir de formas sociais com predomínio específico do econômico que são as empresas capitalistas. Em contrapartida, passaram a existir também certas formações não econômicas, cujo aparelho econômico não é específico nem predominante. Este é o caso das instituições totalitárias, nas quais a reprodução de sua existência material lhes é dada do exterior - é o que o autor chama de extraterritorialidade do aparelho econômico. Sua tese principal é de que 
a inexistência de um aparelho econômico específico tem como conseqüência que todo ato que ocorre em uma instituição totalitária tem um efeito dominante repressivo ou, pelo menos, é repressivo em sua própria base. Tudo nessas instituições tem uma dimensão repressiva. Abandonada a si mesma a repressão enlouquece, pois nenhuma lógica produtiva - com sua racionalidade econômica e seu cálculo, ao menos implícito, dos custos sociais - está presente para servir de camisa-deforça. Tudo o que a ideologia pode fazer, nesses casos, é provocar, através do que reconhece ou desconhece, uma intensa ritualização. (p. 127)

E acrescenta, mais adiante, que:

é necessário admitir que as instituições totalitárias podem ser classificadas em dois tipos distintos: aquelas cuja interpretação mais pertinente exige uma análise em termos de formação ideológica; e as instituições cuja análise mais pertinente se faz em termos de formação repressiva. É preciso, ainda, levar em consideração a situação concreta de certas instituições. $\mathrm{O}$ ponto sensível é, neste caso, a possibilidade, mais ou menos próxima, da constituição de um aparelho econômico (p. 140 - grifos do autor).

Portanto, o critério da extraterritorialidade do aparelho econômico pretende dar conta daquilo que a conceitualização ideal típica de Goffman falhou: o conceito de instituição totalitária. Contudo, alguns pontos não ficam claros ou merecem algumas objeções:

- O primeiro, no que se refere ao conceito de aparelho econômico: seria um sistema de produção de riquezas (produção material), de recursos financeiros, de administração destes recursos? O que lhe seria mais próprio?

- Adotando o critério tão rígido da ausência do aparelho econômico para caracterizar uma instituição como totalitária, certas prisões americanas que reproduzem internamente as condições de sua subsistência material, prisões-empresa que visam o lucro, deixariam de ser instituições totalitárias? Seria correto excluir, por conta deste mesmo critério, as clínicas e os hospitais psiquiátricos particulares no Brasil?

- Embora o autor afirme que não trabalha com determinante em última instância, mas determinação em cada instância, segundo a qual "análise deve sempre ser refeita do ponto de vista de cada efeito" (p. 152), o critério para a distinção das instituições totalitárias coloca-se pela ausência do aparelho econômico (ou pela proximidade). Por isso, seu papel é sempre determinante do maior ou menor (ou talvez nenhum) totalitarismo das instituições - um fator tão importante que, contraditoriamente, passa a funcionar como uma determinação em última instância.

\subsection{Sobre os efeitos da formalização e da análise "perpendicular": cortes verticais e horizontais e a eficácia do esquema proposto}

A que levaria um pensamento tão obsessivamente ligado à ordem? Qual seria sua eficácia? Um efeito de apropriação através da resolução de problemas e sua utilidade concreta, ou a produção problematizante dos espaços abertos das linhas de fuga para novas práticas, novos objetos?

\section{A esse respeito, afirma o autor:}

\begin{abstract}
Apesar das imprecisões, é necessário admitir, com os racionalistas, que é o pensamento que ordena o concreto, mas o ordena no pensamento, o real não é, em si mesmo, nem dinamismo nem ordem, dinamismo e ordem são idéias. $\mathrm{O}$ trabalho do pensamento consiste justamente na produção de uma ordem no caos aparente através da qual o pensamento se apropria inicialmente do real. A essência da teoria consiste na análise desse trabalho de ordenação. Já que é por meio de um trabalho que o pensamento produz ordem (quer se chame compreensão, explicação ou interpretação), ou melhor, um efeito de ordem. A teoria científica se interroga sobre o modo de produção desse efeito de ordem, resultado do trabalho do pensamento apropriando-se do real. (p. 27)
\end{abstract}

Eis o que me parece ser um certo resquício kantiano da ordem da razão, como um transcendental, como uma ordem verdadeira a justificar os cortes epistemológicos nos esquemas euclidianos (espaços fechados) de análise. Por isso, G. A. não hesita em apelar para Parsons, "a despeito do ódio teórico, mas muito sadio, que devemos votar-lhe" (p. 21) pelo muito "que a sociologia deve aos interesses de Parsons pela ordem" (p. 36). Apesar das restrições, será também a Parsons, além de Althusser, que irá apelar para a justificativa de seu esquema de análise ${ }^{8}$ expresso em termos de verticalidades (hierarquia das instâncias que se comandam de cima para baixo e os problemas que se colocam de baixo para cima) (p. $37)$, em cortes perpendiculares.

Este efeito de formalização, este pensamento ordenador que impõe a si mesmo e a seus objetos as prescrições das palavras-de-ordem, centra-se nas suas próprias interdições, nas limitações de sua criação, de sua invenção. A meu ver, será esta função (ou eficácia) dos chamados cortes em seu esquema de análise: as interdições dos limites, das interrupções e das faltas. Nunca a ruptura das irrupções, das emergências, dos novos arranjos, das linhas de fuga de uma ordem estabelecida.

\subsection{Das interdições do pensamento e sua utilidade prática}

Trata-se de pelo menos duas interdições principais: - Não multiplicar as essências na ilusão de que se está apreendendo a totalidade em sua complexidade, mas renunciar de vez à sua apreensão. Ao contrário, a totalidade deve ser fracionada segundo certo modus operandi, buscando sua especificidade de maneira que o resultado da análise dependerá do procedimento analítico.

- Para pensar a realidade, transformando-a, e vice-versa, é necessário renunciar transformar a realidade pelo pensamento. É preciso, portanto, reconhecer que o pensamento se apropria da realidade, mas numa ordem de apropriação que se passa completamente no pensamento. Como conseqüência é preciso renunciar a introduzir a realidade no pensamento e o pensamento na realidade. É a interdição constitutiva do pensamento teórico, para o qual o objeto de pensamento é sempre já uma imagem, na qual se reconhece a realidade, permanecendo, no entanto, imagem (p. 41). 
Uma tal construção teórica, embora se proponha a escapar de essencialismo das totalidades concretas (as instituições enquanto formas são totalidades) para o conhecimento como processo de produção (e o faz através dos cortes e recortes construídos para a análise), acaba por impor outras formas (outras totalidades formais, os modelos) ao pensamento e à própria realidade. Uma garantia de que se está a salvo de toda a ideologia que obscurece com sua turbulência a serenidade verdadeira do pensar científico? Por outro lado, como toda construção teórica, mesmo não exclusivamente lógica, deve ter referência numa realidade (realidade como um estado de coisa e não como um referente), será preciso então estabelecer o tipo de referência entre esta realidade e o objeto produzido pelo esquema formal de análise. Interditando a realidade no pensamento sobra apenas a garantia de correspondência do objeto que se dá por uma imagem de reconhecimento desta realidade, limitada a uma representação - um duplo "sublimado" por abstração. Neste ponto, a questão que se coloca será então: em que medida a representação que reconhece esta realidade é adequada ou não? Seria esta adequação, portanto, o critério de eficácia do conhecimento e da sua veracidade.

Ora, em que medida um pensamento que assim se interdita, que se propõe como garantia o reconhecimento, pode pensar o mundo em transformação? Limita-se aquilo que chama de produção à operação do próprio pensamento, à construção teórica esquadrinhada por cortes verticais e horizontais (planos, níveis e instâncias), ao efeito de apropriação da realidade por representação metafórica, como pode dar conta de um modus operandi de transformação da realidade, ainda que seja no próprio pensamento? Toda proposta de apropriação, de domínio é uma proposta de poder sobre a realidade. Apropriar-se para que e para quem? A suposição de uma verdade como fim a ser atingido move a construção dos modelos fechados de análise - um certo efeito de poder ordenador das formas instituídas da realidade social e, em conseqüência, um reforçamento aperfeiçoado das separações entre teoria e prática, entre trabalho teórico (intelectual) e trabalho prático (manual) que, em última instância, fundam a divisão do trabalho instituída na sociedade de classes.

Ora, se a proposta de Marx era sair do campo das representações para pensar as produções, ele também não precisou expulsar o mundo de suas análises para depois recuperalo nos artifícios formais das estruturas (como se vê em Althusser e em Lacan). Sob este ponto de vista, nosso autor fica no meio do caminho: quer pensar o conhecimento como produção (Marx), mas não consegue sair das representações (imagens-reconhecimento).

\section{Algumas linhas "de fora" para uma análise micropolítica ou uma genealogia das instituições}

Jacques Donzelot (1979), num texto intitulado "The poverty of political culture", apresenta argumentos interessantes para o contraste entre as análises macro e micropolíticas que vêm bem a propósito da intenção deste trabalho. Embora não chame a primeira de macropolítica, ele descreve muitas de suas características, em contraposição ao que denomina como abordagem genealógica:

um tipo de análise que tem muita afinidade com o teatro. Isto ocorre por causa do "status" que ela atribuía realidade. Naquilo que é globalmente dado como real, ela separa a realidade da aparência. Realidade, por exemplo, é classe social ou o Estado. Assim isolada a realidade pode ser posta num palco e passar a desempenhar o papel representativo do real; a realidade atua o real na forma de um número fixo de personagens puros, dotados de conteúdos claros e precisos, com garantia do status de auto-evidência. Na cena da realidade purificada a causalidade pode agora ser introduzida resultando do confronto entre aqueles caracteres ou da introdução de um deus-ex-machina como no teatro arcaico. Haverá luta de classes ou desenvolvimento das forças produtivas, ou ainda o desejo de poder. $\mathrm{O}$ aspecto mais paradoxal deste procedimento está no fato de que estes discursos se apresentam como audaciosos expedientes de extração do real do aperto das representações, para livrá-lo do véu das aparências, mas permitem-se atribuir a esta realidade, desde o ponto de partida, uma natureza auto-evidente. (p. 78)

De outro lado, descreve a análise genealógica como radicalmente diferente:

em vez do teatro, pode-se compará-la com os gêneros literários menores, particularmente aquele das histórias de detetive. Nestas histórias a realidade tem um caráter enigmático. Ela é a priori incompreensível, a surpresa que perturba o conforto, as representações tranqüilas, o crime de desaparecimento que projeta uma nova luz (mas qual?) numa pessoa, numa casa, numa cidade. $O$ procedimento perseguido não é a busca de uma causalidade geral, mas a identificação de indícios. Indícios não são causas, nem mesmo a menor delas. Eles são traços de uma passagem e seguindo o fio que os liga torna-se possível estabelecer a linha ou linhas da transformação que leva à realidade do ponto de partida da investigação. (p. 78)

A realidade para a genealogia ${ }^{9}$ é um invisível-não-escondido, um modo de apresentação, uma referência a ser iluminada ou tornada visível pela constituição de uma superfície de inscrições, através da ligação dos indícios de passagens (como as pegadas) e não relações simbólicas a serem interpretadas em suas causas profundas, escondidas ou recalcadas. Seguir suas trilhas, as linhas de transformação é nunca estacionar nas formas dos estratos sociais (as instituições, por exemplo), é jamais toma-las em si, mesmo quando se considera o contexto de relações com outras formas, mas entender os agenciamentos, as relações de força, os dispositivos de poder que as instituíram como tal. E mais, é preciso deixar claro que micro e macro nada têm a ver com tamanho: o grande - a Sociedade, o Estado, e o pequeno - os indivíduos e suas relações intra e interindividuais, tais como as relações homem-mulher, hétero-homo, professor-aluno, patrão-empregado, enfim, o "pequeno" cotidiano da vida em família, na escola, no hospital, na empresa, a pequena parte ou a unidade. "Não se trata de uma diferença de grau, mas de natureza. Não se trata de uma diferença de tamanho, escala ou dimensão, mas de duas espécies radicalmente diferentes de lógica" (Rolnik, 1989, p. 59). 
Micro refere-se à dimensão do processo de constituição das formas da realidade: a realidade em vias de se instituir, se definir e se desmanchar (se desterritorializar) ao mesmo tempo. Enquanto macro refere-se à realidade em suas formas constituídas - aqui também, tanto no nível individual, quanto grupal ou coletivo ${ }^{10}$. É na lógica das formas constituídas que se pensa em termos de um todo, de pólos em conflito e/ou contradição - em suma, em relação de dominação entre Estado e Sociedade quanto para as relações de dominação no seio de um casal. (p. 6-7)

Este relevo de uma macropolítica aparece claro no livro Instituição e Poder. G. A. pensa o poder do ponto de vista de matriz única de dois (dominante e dominado), identificado ou predominantemente localizado num aparelho repressivo, que se irradiaria por todas as ramificações das formações sociais. Identificado o poder como forma e não como força (ou melhor, relação de forças) não sobra referência para um contrapoder, ou quando raramente aparece ele é exterior ao poder, o lugar da grande recusa, uma espécie de "lei revolucionária". Ora, se o poder não é forma e não se localiza num ponto e, como relação de forças atravessa todos os pontos (Foucault, 1980), a resistência (ou contra-poder) não lhe é exterior, é a possibilidade imanente às próprias relações de poder. Pensar o poder enquanto produtor de técnicas de subjetivação através dos dispositivos que engendra em seus agenciamentos, "é pensá-lo segundo uma outra lógica ${ }^{11}$, que permite, por exemplo, lutar contra a reificação da consciência e apreender a dimensão da criatividade social" (Rolnik, 1990, p. 6-7). Parafraseando Foucault (1974, p. 101), não há sobre-lucro se não houver subpoder, o que significa dizer que um certo tipo de produção de subjetividade é tão importante quanto as produções econômicas para o funcionamento do que F. Guattari (1981, p. 211) chama de Capitalismo Mundial Integrado (CMI). Esta micropolítica de processos de subjetivação refere-se, segundo Deleuze e Guattari, à questão de uma análise das formações do desejo no campo social, desejo que se efetua no agenciamento - desejo-agência, desejo-máquina que nada tem a ver com alguma ordem natural ou espontânea, com a falta ou a lei, com o desejo do desejo hegeliano, com prazer ou com a festa (Deleuze \& Guattari, 1972).

Conceitos aparentados, poder e desejo merecem neste ponto algumas considerações, já que permeiam todos os operadores da análise (micro-análise). Ambos mantêm o mesmo caráter de imanência, o mesmo sentido afirmativo, pré-individual, pré-pessoal. Sob estes aspectos, podem ser considerados conceitos vicariantes. Sobre esta coincidência, afirma Baudrillard (1984) que o mérito de Vigiar e punir e Vontade de saber, de Michel Foucault, é o de

substituir a concepção negativa, reacional transcendente do poder, fundado sobre a proibição e a lei, por uma concepção positiva, ativa, imanente, o que é efetivamente capital. Fica evidente a coincidência entre esta nova versão do desejo proposta por Deleuze ou Lyotard: não mais a ausência ou a proibição, mas o dispositivo, a disseminação positiva dos fluxos e das intensidades. Esta coincidência não é acidental: significa simplesmente que em Foucault o poder ocupa o lugar do desejo. ${ }^{12}$ (p. 25-26)
Ao contrário das concepções reichianas ou freudomarxistas para as quais "desejo e poder tinham sinais contrários; hoje micro-desejo (do poder) e micropolítica (do desejo) se confundem literalmente nos confins da libido: basta miniatuarizar" (p. 27).

Discordando do sentido que se pode apreender do termo miniatuarizar, é preciso deixar claro novamente que as noções de micro e macro, segundo a perspectiva aqui apresentada, nada têm a ver com tamanho, assim também todo o processo de desmontagem não se faz a partir das formas constituídas, mesmo parciais, fracionadas pelos operadores da análise. Tampouco resulta na proposição de outras formas já purificadas, melhores para a resolução de problemas teóricos e a demonstração (ou prova) de sua "utilidade prática nas análises concretas", como nos adverte G. A. antes mesmo do prefácio de seu livro. A genealogia não se preocupa com resultados ou soluções. Assim também que ela promove é diagonal, o que significa o abandono de todo tipo de esquadrinhamento horizontal e/ou vertical da análise, porque este prioriza as formas instituídas como um dado ${ }^{13}$, um pressuposto de análise, num espaço fechado das fixações e das identidades tomadas como especificidades. A desmontagem transversal é oblíqua, pensa os processos, as produções não a partir das formas e do fracionamento delas, como propõe G. A., mas de uma topologia do espaço aberto, a cartografia dos múltiplos agenciamentos, das relações coletivas de práticas de corpos, das enunciações também coletivas e dos devires reais de suas diferenças.

Cioso em resguardar os critérios de cientificidade, ou talvez por desconhecer o significado do termo transversalidade em sua dimensão micropolítica, é que G. A. acusa a análise institucional de tomar "as instituições em todas as suas determinações ao mesmo tempo" (p. 13), como para dar conta da totalidade. A transversalidade é um conceito operador que se expressa por índices de abertura ou fechamento dos grupos e das situações institucionais concretas, em termos de expressão coletiva da produção desejante (a dimensão instituinte), esta sim considerada ao mesmo tempo política-sexual-econômica-ideológica (Guattari \& Rolnik, 1986). Não se trata, pois, de conceituar a instituição, muito menos de considerá-la em sua totalidade concreta ou multiplicando propriedades (Goffman), mas de trabalhar os processos genealógicos que a atravessam enquanto forças instituintes das singularidades pré-individuais, nos momentos muito especiais da análise (momentos analisadores) ${ }^{14}$

Todo o esforço até agora despendido com a finalidade de discernir entre as análises micro e macropolíticas pode deixar escapar uma idéia de demarcação restrita e abstrata de planos, níveis ou campos de análise, o que de alguma forma contraria o modus operandi do pensamento transversal e seu caráter intrínseco de transdisciplinaridade. Guattari nos apresenta o argumento contrário ao jogo dessas oposições, através do cruzamento de duas noções: "Nunca usar um só modo de referência“ (Guattari \& Rolnik, 1986, p. 132). E mais:

Essa oposição entre molar e molecular pode ser uma armadilha. Eu e Gilles Deleuze sempre tentamos cruzar essa oposição 
com uma outra, a que existe entre micro e macro. As duas são diferentes. O molecular, como processo, pode nascer no macro. O molar pode instaurar o micro. (p. 128). tante:

E isto vale para qualquer trabalho seja teórico, seja mili-

Eu posso, por exemplo, ficar nesta tribuna pronunciando grandes discursos emancipadores e liberadores e, ao mesmo tempo, ter um investimento de poder paranóico para me apoderar do auditório, estabelecer uma relação de sedução falocrática, racista e sei lá o que mais (...). Nesse caso, o que acontecerá, infalivelmente, é que as melhores intenções, as relações de força mais favoráveis, vão ter, mais cedo ou mais tarde, um encontro marcado com uma experiência de poder. E, inversamente, se os processos de revolução molecular não forem retomados ao nível das relações de força reais (relações de forças sociais, econômicas, materiais) pode acontecer de eles começarem a girar em torno de si mesmos, como processos de subjetivação em implosão, provocando um desespero que pode levar ao suicídio, à loucura ou a algo no gênero. (p. 132)

Portanto, se os problemas se constituem ao mesmo tempo nos dois processos, o molar e o molecular, e a análise micropolítica se situa no cruzamento dos dois, haverá sempre que se considerar a multiplicidade. Nada justificaria colocar, de um lado, o molecular todo o bem (ou toda a verdade) e, de outro, o molar todo o mal (ou toda a falsidade), ou vice-versa, como às vezes acontece nas "simplificações" de certas análises teóricas e/ou militantes.

Pensar as transformações, as desmontagens transversais das formas instituídas é também pensar os agenciamentos instituintes, não apenas para reconstituir indícios (como nas histórias de detetive, mencionadas por Donzelot) e iluminar o invisível-não-escondido das linhas de transformação. É que esta provocação de visibilidade é também uma ética, uma outra ética, uma ético-estético-política de novos modos de existência (Guattari, 1990), num mundo para sempre inacabado. No lugar de uma utopia regulada por um modelo teleológico de perfeição definitiva e acabada, ou da nostalgia das origens (uma terra prometida ou um paraíso perdido), uma ética ontológica do real, sem modelos, a fazer pulular as diferenças, onde as alianças solidárias multipliquem o heterogêneo, o ilimitado, e se comprometam definitivamente com a finitude.

\section{Referências}

Albuquerque, J. A. G. de (1980). Instituição e poder: a análise concreta das relações de poder nas instituições ( $2^{\underline{a}}$ ed.). Rio de Janeiro: Graal.

Althusser, L. (1985). Aparelhos ideológicos: nota sobre os aparelhos ideológicos de Estado (2 $2^{\mathrm{a}}$ ed.). Rio de Janeiro: Graal.

Baudrillard, J. (1984). Esquecer Foucault. Rio de Janeiro: Rocco.

Deleuze, G., \& Guattari, F. (1972). L 'anti-Oedipe: capitalisme et schizophrénie. Paris: Editions de Minuit.

Donzelot, J. (1979). The poverty of political culture. Ideology \& Consciousness, $5,73-86$.

Foucault, M. (1974). A verdade e as formas jurídicas. Cadernos da PUC/RJ, 16 , $5-45$.

Foucault, M. (1977). Vigiar e punir. Petrópolis: Vozes.

Foucault, M. (1980). História da sexualidade: a vontade de saber. Rio de Janeiro: Graal.

Foucault, M. (1992). Microfísica do poder. Rio de Janeiro: Graal.

Goffman, I. (1974). Manicômios, prisões e conventos. São Paulo: Perspectiva.

Guattari, F. (1981). Revolução molecular: pulsações políticas do desejo. São Paulo: Brasiliense.

Guattari, F. (1990). As três ecologias. Campinas: Papirus.

Guattari, F., \& Rolnik, S. (1986). Micropolítica: cartografias do desejo. Petrópolis: Vozes.

Rolnik, S. (1989). Cartografia sentimental: transformações contemporâneas do desejo. São Paulo: Estação Liberdade.

Rolnik, S. (1990, 8 de setembro). Para uma ética de real. Jornal do Brasil (Caderno Idéias/Livros), p. 6-7.

Veyne, P. M. (1982). Foucault revoluciona a história (apêndice). Como se escreve a história. Brasília: Universidade de Brasília.

Termo usado por Guilhon de Albuquerque para as instituições totais de Goffman.

2 Em face da citação repetida do autor de Instituição e Poder, Guilhon de Albuquerque, usarei doravante as iniciais G. A.

3 Embora pareça oscilar entre esta concepção de conhecimento como produção e a de conhecimento por representação, conforme será discutido mais adiante.

4 Ver as páginas 13, 14, 25 e 26 de Instituição e poder (Albuquerque, 1980).

5 Dentre esses atributos: ruptura das barreiras que separam as três etapas da vida -dormir, brincar, trabalharrealizadas num mesmo local; controle das necessidades e vigilância; controle das comunicações e informações; separação e hostilidade entre o grupo controlado e a equipe dirigente; uso do trabalho como recompensa ou castigo; incompatibilidade com a vida familiar etc., ver Goffman (1974).

6 Trata-se, em primeiro lugar, de falar de instituição como lugar destacado da sociedade englobante, como um lugar de soberania. E, em segundo lugar, do modo de administrar necessidades coletivas, o que significa falar de relações sociais. Ver Albuquerque (1980, p. 92)

7 É neste ponto que Guilhon de Albuquerque critica Althusser, quanto ao papel da ideologia na reprodução da força de trabalho que, embora lembre "que a ideologia não existe fora de seu suporte material", confunde atitudes, comportamentos, condutas e rituais etc.; tudo compreendido na categoria de práticas ideológicas (Albuquerque, 1980, p. 5). 
8 A forma espacial do esquema de análise encontra-se nas páginas 43, 44 e 47 a 49 do referido livro Instituições e Poder (Albuquerque, 1980).

9 Ver, a respeito da genealogia, principalmente, Foucault em "Vigiar e punir" (1977) e "Nietzsche: genealogia e história" (1972), além de Veyne (1982) em "Foucault revoluciona a história".

${ }^{10}$ Os fenômenos de massa, como os que varreram o mundo (ou boa parte dele) em 1968, são fenômenos que só podem ser bem compreendidos se considerados fluxos instituintes em sua lógica "micro". Gabriel Tarde, autor tão desprezado pelos estudos sociológicos, talvez tenha sido o primeiro a descrever, pelo contágio da imitação, este fluxo (micro) dos fenômenos de massa.

11 Uma lógica da não-contradição (porque não é dialética), das positividades e dos paradoxos do terceiro incluso, no qual A pode ser A e B, ao mesmo tempo.

12 Esta correspondência tão estrita entre poder e desejo que, para Baudrillard parece tão evidente, é discutível. Contudo, não é intuito deste trabalho discutir esta questão.

13 A auto-evidência mencionada no texto de Donzelot (1979).

14 É possível que Guilhon de Albuquerque tenha razão em suas críticas a certas práticas de alguns que se autodenominam "analistas institucionais" que, ao fracionarem as análises, crêem estar provocando as diferenças e promovendo transformações.

Lilia Ferreira Lobo, doutora em Psicologia pela Pontifícia Universidade Católica do Rio de Janeiro, é professora no departamento de Psicologia da Universidade Federal Fluminense. Endereço para correspondência: Rua Senador Vergueiro, 157, apto. 905. Rio de Janeiro/RJ - CEP22.230-000. E-mail: devircrianca@ig.com.br 